\title{
The Craniofacial Dismasking Flap: A Retrospective Study
}

\author{
Muñoz, Ruben ${ }^{1,2^{*}}$ (D), Golaszewski, Jose ${ }^{3}$ and Diaz, Alvaro 3 \\ ${ }^{1}$ Chief Surgeon, Oral and Maxillofacial Surgery Department, "Dr ANGEL LARRALDE" University Hospital, \\ Carabobo University, Naguanagua, Venezuela \\ ${ }^{2}$ Director of Program, Oral and Maxillofacial Surgery, Carabobo University, Venezuela \\ ${ }^{3}$ Oral and Maxillofacial Surgeon, "Dr ANGEL LARRALDE" University Hospital, Carabobo University, \\ Naguanagua, Venezuela
}

*Corresponding author: Muñoz G, Ruben E, MS, DDS, Chief Surgeon of Oral and Maxillofacial Surgery, Department at "Dr ANGEL LARRALDE" University Hospital, Carabobo University, Naguanagua, Altos de la Colina de Bárbula 15-25, Naguanagua, Carabobo, 20-42, Venezuela, Tel: +58-414-400-0602

\begin{abstract}
Purpose: The aim of this work is to study the use of this technique for extirpation of malignant tumors of the maxillary sinus and application for a variety of facial lesions, craniofacial deformities and trauma sequel. This includes the exposure for adequate tumor resection and the preservation of tissues and they function. This approach was evaluated including the advantages and disadvantages regarding the function, aesthetic outcome and the complications related to the procedure.
\end{abstract}

Materials and methods: Eight patients underwent the Dismasking flap approach for excision of tumors and craniofacial reconstruction during the period from 2011 to 2016 at the Dr. Angel Larralde Universitary Hospital, Valencia Venezuela. This procedure uses 8 basic incisions; bicoronal incision, upper eye lid approach, lower lid approach, bilateral inter-cartilaginous incision, septocolumellar-complete transfixion incisions and maxillary vestibular approach and depending on the surgeon needs a preauricular rhytidectomy approach.

Results: All patients successfully underwent the planned procedures through the dismasking flap approach for the treatment of lesions and craniofacial reconstruction without significant complications. Eight of the patients had immediate postoperative face edema which resolved within a week. Lagoftalmus occurred in two patients and resolved in a three weeks period. Other sequelae were nasal crusting and infraorbital hypo-esthesia. No motor function damage was evidenced.

Conclusion: The Dismasking flap approach offers a good exposure of the upper and middle third of the face with excellent cosmetic results. In conclusion this approach is a useful tool in the management of craniofacial fractures, resection of tumors of the anterior cranial fossa, microvascular surgery and facial transplant. This approach may be combined with down fracture of the maxilla for accessing, exposing and resecting sinonasal malignancies. The dismasking flap technique can be considered as a valuable procedure with low morbility and excellent cosmetic outcome.

\section{Keywords}

Approach, Dismasking, Cranioorbitofacial reconstruction, Tumors resection

\section{Introduction}

The Craniofacial approaches can be used for the radical resection of lesions in the middle and anterior cranial fossa. Tessier [1-3] worked on the reconstruction of birth defects and laid the groundwork for the use of craniofacial approaches for the correction of pediatric deformities. Derome, [4] and Tessier were pioneered craniofacial approaches for correction of deformities and resection of tumor lesions in the anterior and middle cranial fossa. These approaches are carried out in adults, but their use in children requires a modification to avoid endangering craniofacial growth $[1,5]$.

In 1993, Tajima, et al. reported the application of a new skin preparation technique, "facial dismasking flap," in facial reconstructive surgery [6]. The technique involves a combination of coronal and circumpalpebral incisions. With this technique, the facial skin together with the facial nerves and muscles is "Dismasked," that is, peeled inferiorly, and a wide exposure of the facial

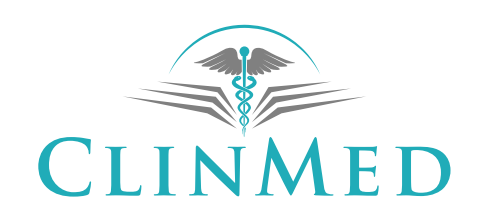

INTERNATIONAL LIBRARY

Citation: Ruben M, Jose G, Alvaro D (2021) The Craniofacial Dismasking Flap: A Retrospective Study. Res Rep Oral Maxillofac Surg 5:047. doi.org/10.23937/2643-3907/1710047

Accepted: January 27, 2021, 2020; Published: January 29, 2021

Copyright: (c) 2021 Ruben M, et al. This is an open-access article distributed under the terms of the Creative Commons Attribution License, which permits unrestricted use, distribution, and reproduction in any medium, provided the original author and source are credited. 
skull is established without damaging the facial nerve. Scars on the face are only left around the eyelid. This method has been used to remove tumors in the head and neck areas, [7-10] but is not yet widely used.

In 2011, Muñoz, et al. [11,12] described a clinical indication for the use of craniofacial Dismasking flap and the modification of the bicoronal incision making many curves was made to hide the scar in the cranial area, and preseptal dissection in the upper and lower eye lid for terminal facial nerve protection.

The present report described a retrospective study of the surgical technique, indications and results of craniofacial Dismasking flap application for a variety of facial lesions, craniofacial deformities and trauma sequel.

\section{Materials and Methods}

The Dismasking flap approach has been used in our Centre for the treatment of eight patients for excision of tumors, craniofacial reconstruction for craniofacial deformities and craniofacial trauma sequel.

A retrospective study was performed for eight patients who had undergone the Dismasking Flap approach during the period from 2011 to 2016 at the Dr. Angel Larralde Universitary Hospital, Valencia Venezuela.

All patient's records included clinical studies, radiographs evaluation, CT scan and photographs analysis, pre- and postoperative. All the procedure was done under general anesthesia with oral intubation, submandibular derivation or traqueostomy.

We also postoperatively evaluated facial scarring and facial movements. The Facial movement was assessed according to the House-Brackmann [12] grading system.

"This study was approved by the Carabobo University and Dr. Angel Larralde Universitary Hospital IRB and all participants signed an informed consent agreement".

\section{Surgical Technique}

\section{Step 1: Protection of the Globe and preparation}

Protection of the cornea during operative procedures around the orbit may reduce ocular injuries. If one is operating on the skin side of the eyelids to approach the orbital rim and/or orbital floor, a temporary tarsorhaphy or scleral shell may be useful. These are simply removed at the completion of the operation. One\% lidocaine with 1:80,000 adrenaline is infiltrated.

\section{Step 2: Locating the line for bicoronal incision}

It is necessary the evaluation of the case. The sex, Age, hairline of the patient and preoperative diagnostic are factors to be evaluated for designing the line and ubication of incision. The coronal incision can be extended inferiorly to the level of the lobe of the ear as a preauricular incision.
Extensive shaving of the head before incision is not medically necessary. The presence of hair makes closure more difficult. If shaving the hair is desired, it doesn't need to be extensive.

The bicoronal incision and dissection is carried till the supraorbital region. Is important the preservation of the pericranium in cases of craniofacial deformities or craniotomy.

Is necessary the infiltration of anesthetic with vasoconstrictor into the subgaleal plane. The use of Raney clips is needed before to make the incision in order to minimize the blood loss (Figure 1).

In this approach is used the method of finger for dissection of areolar tissue in the subgaleal plane.

The supraorbital and supratrochlear nerves are marked with 7-0 nylon and divided.

\section{Step 3: Orbital incision}

At orbital level, a blepharoplasty incision is made (Dr. Epker's technique) with the subsequently submuscular dissection (between orbicularis muscle and orbital septum), and exposure of the infraorbital and supraorbital rim. The skin and orbicularis muscle flap remain attached to the bicoronal flap.

The infraorbital nerve is marked with 7-0 nylon and divided. In this manner the upper and lower eyelids, including the orbicularis oculi muscle, are elevated with the flap; however, all lacrimal systems remain in place (Figure 1).

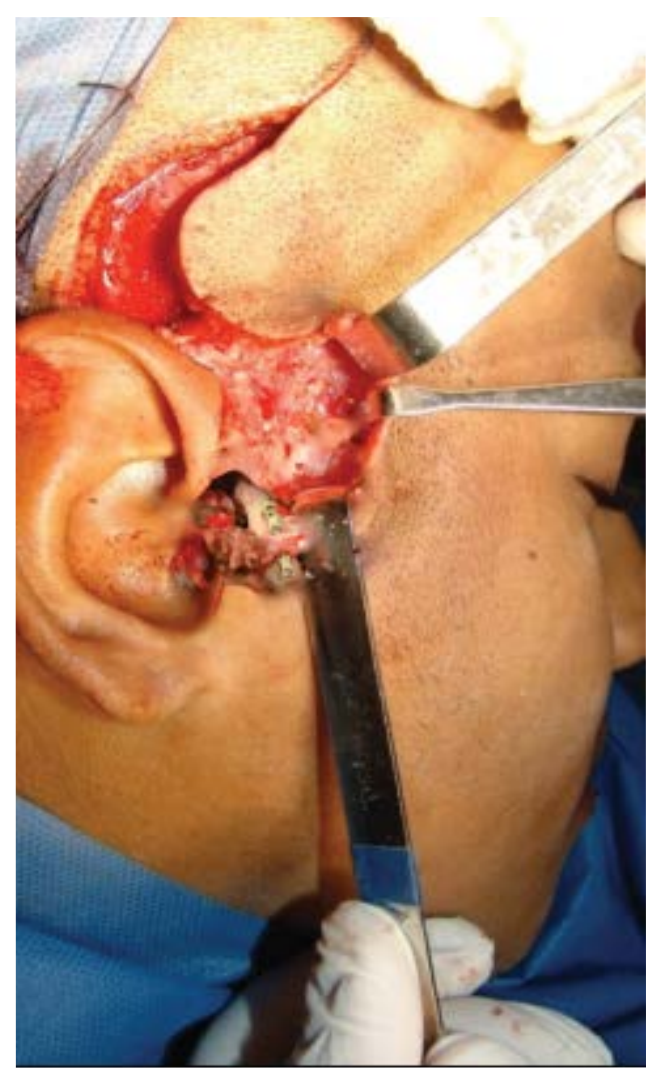

Figure 1: Bicoronal approach with preauricular extension. 


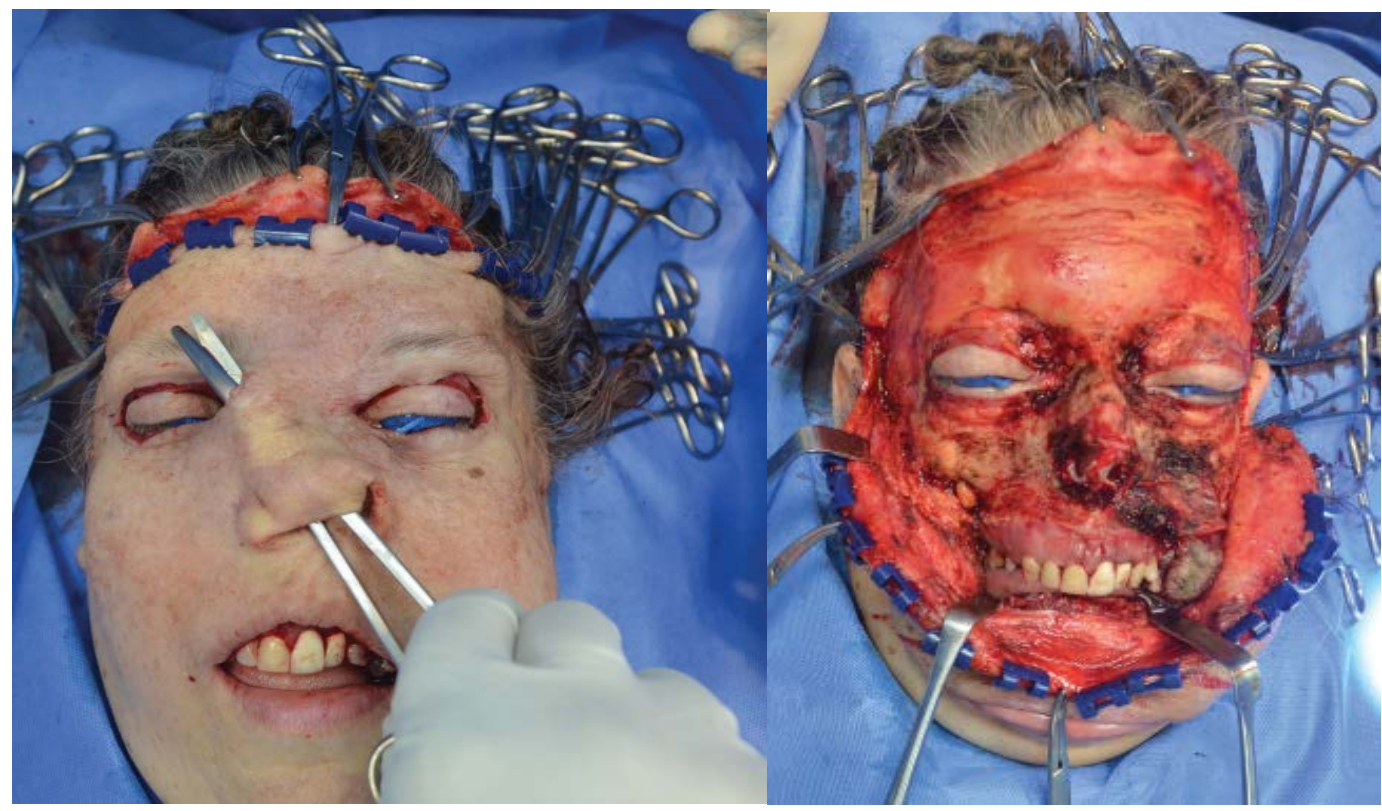

Figure 2: Intraoperative photographs of Craniofacial Dismasking flap (A) Bicoronal incision, Palpebral incision and endonasal incision and (B) Facial exposure by Dismasking flap.

\section{Step 4: Endonasal approach}

An incision is made endonasal supracartilaginosa to allow dissection and expose the structures of the upper and middle face of the nasal dorsum.

When the infraorbital neurovascular bundle is sectioned and the margins of the piriform are completely exposed, all the structures of the upper two thirds of the maxillofacial region can be displayed directly to the dentoalveolar portion (Figure 2).

(At the end of the surgery the infraorbital nerve and sectioned supraorbital nerve are anastomosed).

\section{Step 5: Vestibular maxillary approach}

The incision is usually placed approximately $10 \mathrm{~mm}$ superior to the mucogingival junction. The surgeon should not make the incision higher in the anterior region due to the piriform aperture. The incision extends as far posteriorly as necessary to provide exposure, usually till second premolar. The incision extends transversal in mucosa, submucosa, facial muscles and periosteum. There was connected with the others approaches by subperiosteal dissection (Figure $2 b$ ).

\section{Step 6: Preauricular rhytidectomy approach}

The incision is outlined at the junction of the facial skin with the helix of the ear. The incisions extend inferiorly to mandible angle or posteriorly to the ear. This is made through skin and subcutaneous connective tissues to the depth of the temporalis fascia (superficial layer). At this point, the superficial musculoaponeurotic layer (SMAS) is incised. The parotid capsule is exposed and dissection of layer is made till the exposure of the posterior mandibular border.

A nerve stimulator is used, and provides muscle con- traction, is used when motor nerve graft transference is performed. It is performed in motor and mixed motor nerves transected and repaired before 72 hours of traumatic event. For ubication of facial nerve branches is necessary the use of the reference described for $\mathrm{Al}$ Kayat [13].

\section{Results}

All patients successfully underwent the planned procedures after the craniofacial Dismasking flap approach for the treatment of Benign and malignant lesions and trauma sequel or upper and middle third (Table 1).

In all cases, sufficient surgical fields were made to remove the tumors and make reconstructions (frontal reconstruction with free fibula flap + Parietal bone graft. Facial nerves were anatomically preserved in all patients without preauricular extention, and facial mimic was normal. In two cases of panfacial sequeal with subcondylar fracture the dismasking flap was extended with preauricular rhytidectomy approach and the facial nerve was dissected for open reduction of the fracture. Only 1 patient had lesion of the facial nerve III/IV according to the House-Brackmann grading system [14].

In all cases of tumor and trauma sequel an intraoral approach was performed for total exposure of middle facial third.

Scars on the face were negligible in all patients, and none of them complained about facial scarring (Figure 3).

Mean hospital stay was 8.2 days with a minimum of 7 days and a maximum of 15 days. No postoperative complications such as epistaxis, vestibular stenosis, or aesthetic problems of the nose were seen.

Following the patients after completion of post-operative period revealed a well vascularized soft tissue 
Table 1: Data of 8 Cases Who Underwent Craniofacial Dismasking Flap Technique.

\begin{tabular}{|l|l|l|l|l|l|l|}
\hline Patient & Age & Sex & Diagnostic & Treatment & Intubation & Facial palsy \\
\hline $\mathbf{1}$ & 65 & F & Maxillary adenocarcinoma & Tumor resection & Tracheostomy & HB III-IV \\
\hline $\mathbf{2}$ & 45 & F & Osteosarcoma & Tumor resection & Tracheostomy & NO \\
\hline $\mathbf{3}$ & 21 & M & Panfacial fracture sequel & ORIF + bonegraft & Submental & NO \\
\hline $\mathbf{4}$ & 25 & M & Panfacial fracture sequel & ORIF + bonegraft + Lefort I & Submental & NO \\
\hline $\mathbf{5}$ & 22 & M & Panfacial fracture sequel & ORIF + bonegraft & Submental & NO \\
\hline $\mathbf{6}$ & 26 & M & Rhabdomyosarcoma & Rabdomiosarcoma & Oral & NO \\
\hline $\mathbf{7}$ & 34 & F & Adenocarcinoma & Tumor resection & Tracheostomy & NO \\
\hline $\mathbf{8}$ & 35 & F & Malignant melanoma & Malignat Melanoma & Oral & NO \\
\hline
\end{tabular}
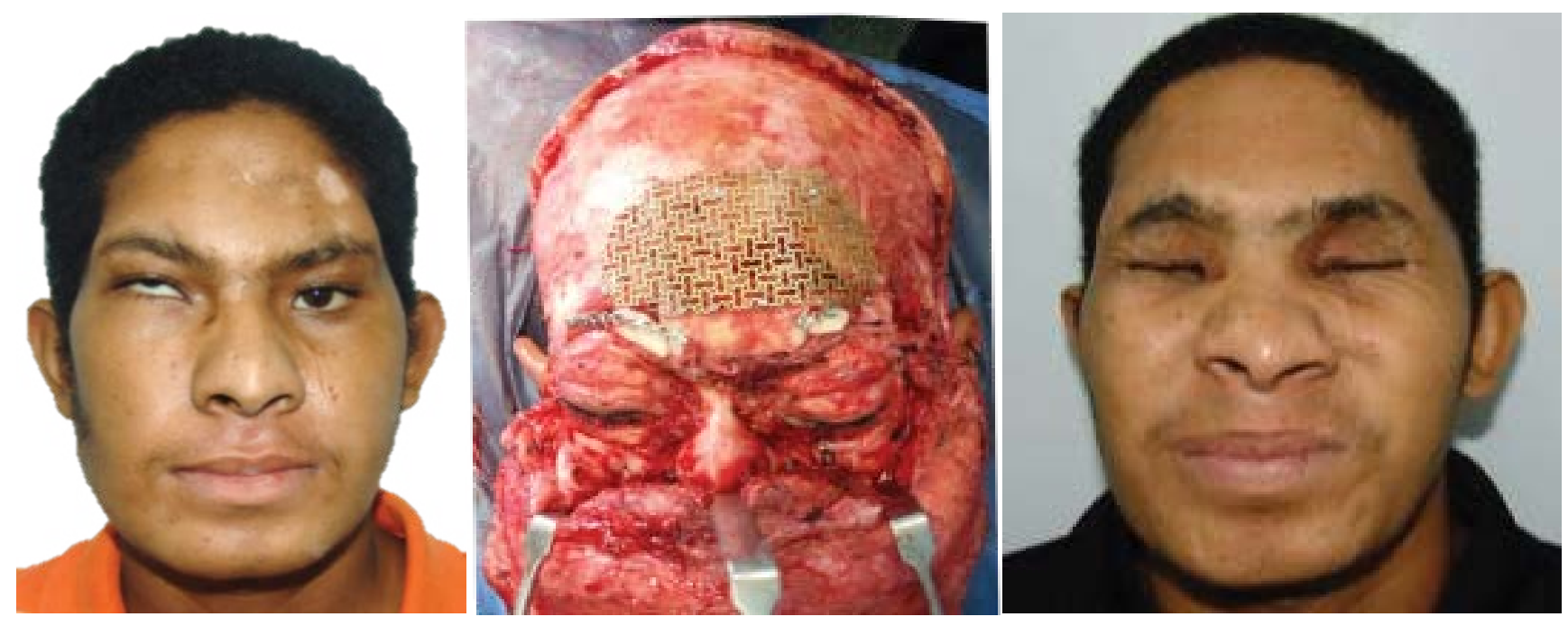

Figure 3: Facial nerve preservation. The patient's face before of surgery (left) and 24 months after the surgery (right).

of the face. There was no skin contracture, epiphora or ectropion of the lower eye lid secondary to cicatrization of incisions.

\section{Discussion}

Surgical techniques of craniofacial approaches were implemented by Tessier for the reconstruction of the craniofacial region in patients with birth defects and for the correction of pediatric facial deformities. Tessier and Derome also proposed craniofacial surgical approaches for the resection of lesions in the anterior and middle cranial fossa $[2,3]$.

The surgical approach of the Dismasking flap was developed for the removal of tumor lesions not only located in the skull but also in the facial region and in surgeries that require extensive surgical fields. Because in other types of approaches they present limitations in the surgical field and show postoperative cosmetic results in the facial region [15-17].

In addition, with the dismasking flap approach, it is possible to resect tumors of the anterior cranial base that extend to the nasal, orbital and maxillary regions, allowing other surgical procedures such as partial or vertical partial maxillectomy (Stage T1 or T2 tumors), total maxilectomy (stages T2 and T3) and maxilectomy enlarged to the skin, orbit, infrasphenotemporal fossa and skull base in neoplasms invading the skin, orbit, retromaxillary region or base of the skull $[9,18-20]$.

This technique of surgical approach has a disadvantage the frequent lagosphthalmos that occurs in the postoperative produced by lack of transoperative hydration of the orbicularis oculi muscle. Intraoperative exposure of the muscle can lead to its desiccation and cause an injury that is usually irreversible, in addition to the risks involved in a dissection of the anatomical structures [7-14,20,21]. In addition, supramuscular dissection with lesion of the terminal branches of the facial nerve affects the contraction and tone of the sphincter function of the periorbital area [22].

The advantage of the facial dismasking flap is to provide a wide exposure of the facial skull while preserving the facial nerves and muscles. The upper and middle part of the face can be totally exposed and lesions can be approached both anteriorly and laterally under a sufficient surgical field. Therefore, with facial dismasking, even large tumors in these areas, such as a maxillary tumor extending into the infratemporal fossa or an anteriorly extending tumor in the infratemporal fossa, can be removed $[11,14,22]$.

Houseman, et al. observed that the majority of the facial skin is supplied by paired superficial temporal, 
transverse facial, and facial arteries [23]. This allowed us to demonstrate that the flow from the adjacent superficial temporal, transverse facial, and facial arteries (through the angular artery) territories can supply the supraorbital and supratrochlear regions of the central forehead. Similar reversal of flow has been demonstrated in models where the internal carotid artery is occluded [22,24-26].

Calvarial grafts from the parietal region was harvested in three of our cases for orbital floor reconstruction in two cases and for frontonasal augmentation in one case, with no complications observed in any of our patients. Frodel, et al., in the anatomical and technical considerations and morbidity of coronal approach have stated that permanent sensory deficits are relatively common and difficult to quantify $[27,28]$. Scalp anesthesia and paraesthesia are unavoidable. Due to this, in all cases the nerves were sectioned in the approach.

\section{Conclusions}

The Craniofacial Dismasking approach is a useful tool in the management of craniofacial fractures, resection of tumors of the anterior cranial fossa and middle third of the face.

However, this Dismasking flap approach allows a surgical procedure with a large margin of safety due to the wide direct visualization of the tissues, besides offering aesthetic advantages, proven recovery of motor and sensory functions, nervous tissue and muscle functions.

This approach is an alternative to tumors resection and craniofacial reconstruction with excellent cosmetic results, is a feasible procedure with low morbidity and excellent cosmetic results and also helps to make an immediate reconstruction with bone grafts, alloplastic grafts, microvascular flaps. It should be incorporated into the oncological and maxillofacial surgical armamentarium to avoid not aesthetic incisions (Webber Fegurson approach).

\section{Funding}

None.

\section{Conflict of Interest}

None declared.

\section{Ethical Disclosure Protection of People and Animals}

All procedures performed in studies involving human participants were in accordance with the ethical standards of the institutional and/or national research committee and with the 1964 Helsinki declaration and its later amendments or comparable ethical standards.

\section{Confidentiality of Data}

The authors declare that they have followed the protocols of their workplace on the publication of data from patients and that all patients included in the study have received sufficient information and have given their written informed consent to participate in the study.

\section{Right to Privacy and Informed Consent}

The authors have obtained the informed consent of patients and/or subjects referred to in the article. This document is in the possession of the author of correspondence.

\section{Acknowledgment}

None.

\section{References}

1. Tessier $P$ (1969) Complete and forme fruste vertical and oblique orbito-facial clefts (colobomas). Ann Chir Plast 14: 301-311.

2. Tessier $P$ (1971) The definitive plastic surgical treatment of the severe facial deformities of craniofacial dysostosis. Crouzon's and Apert's diseases. Plast Reconstr Surg 48: 419-442.

3. Tessier P, Guiot G, Rougerie J, Delbet JP, Pastoriza J (1967) Cranionaso-orbito-facial osteotomies. Hypertelorism. Ann Chir Plast 12: 103-118.

4. Derome $P$ (1977) The trans-bucco-pharyngeal approach and tumoral pathology of the clivus. Neurochirurgie 23: 298-306.

5. Barone CM, Jimenez (1996) Special considerations in pediatric cranial fixation: A technical overview. J Craniomaxillofac Trauma 2: 42-47.

6. Tajima S, Tanaka Y, Imai K, Ueda K, Maejima S, et al. (1993) Extended coronal flap-"dismasking flap" for craniofacial and skull base surgery. Bull Osaka Med Coll 39: 1-8.

7. Imai K, Komune H, Nomachi T, Fujimoto T, Fujii M (2002) Approach of the craniofacial region using a dismasking flap. Jpn J Head Neck Cancer 28: 597-601.

8. Imai K, Tsujiguchi K, Toda C, Sung KC, Tajima S, et al. (1997) Osteoblastoma of the nasal cavity invading the anterior skull base in a young child. Case report. J Neurosurg 87: $625-628$

9. Kishimoto S, Tsunoda A, Koda H (2010) Nasal downward swing approach coupled with the facial dismasking flap. Auris Nasus Larynx 37: 217-219.

10. Koda H, Tsunoda A, lida H, Akita K, Kishimoto S (2007) Facial dismasking flap for removal of tumors in the craniofacial region. Laryngoscope 117: 1533-1538.

11. Muñoz R, Golaszewski J, Diaz A (2011) El Desguantecrane orbitofacial como abordaje craneofacial y sus aplicaciones clínicas. Acta Odontológica Colombiana 3: 81-91.

12. Muñoz R, Golaszewski J, Diaz A (2012) The crane orbit ofacial dismasking flap as craniofacial approach. Case Report. Numero 2 Julio Diciembre Año 13: 43.

13. Al kayat A, Bramley $P$ (1997) Amodified pre-auricular approach to the temporomanbilar joint and malar archa. $\mathrm{Br} \mathrm{J}$ Oral Maxillofacial Surg 17: 91.

14. House JW, Brackmann DE (1985) Facial nerve grading system. Otolaryngol Head Neck Surg 93: 146-147.

15. Liu JK, Decker DB, Schaefer SD, Moscatello AL, Orlandi $\mathrm{RR}$, et al. (2003) Zones of approach for craniofacial resection: Minimizing facial incisions for resection of anterior cranial base and paranasal sinus tumors. Neurosurgery 53: 1126-1137. 
16. Ozer E, Bapna S, Agrawal A, Schuller DE (2010) Maxillary removal and reinsertion: A favorable approach for extensive anterior cranial base tumors. Otolaryngol Head Neck Surg 142: 322-326.

17. Bozza F, Nisii A, Parziale G, Sherkat S, Del Deo V, et al (2010) Transnasal endoscopic management of frontal sinus mucopyocele with orbital and frontal lobe displacement as minimally invasive surgery. J Neurosurg Sci 54: 1-5.

18. Greenfield JP, Anand VK, Kacker A, Seibert MJ, Singh A, et al. (2010) Endoscopic endonasal transethmoidal transcribriform transfovea ethmoidalis approach to the anterior cranial fossa and skull base. Neurosurgery 66: 883-892.

19. Raza SM, Garzon Muvdi T, Boaehene K, Olivi A, Gallia G, et al. (2010) The supraorbital craniotomy for access to the skull base and intraaxial lesions: A technique in evolution. Minimally Invasive Neurosurgery 53: 1-8.

20. Ueda K, Tajima S, Oba S, Tanaka S, Omiya Y, et al. (2000) Recovery of forehead sensation after extended coronal flap or "dismasking flap." Eur J Plast Surg 23: 146-149.

21. Har EI G (2004) Anterior craniofacial resection without facial skin incision-a review. Otolaryngol Head Neck Surg 130: $780-787$

22. Ammirati M, Bernardo A (1998) Analytical evaluation of complex anterior approaches to the cranial base: An anatomic study. Neurosurgery 43: 1398-1408.
23. Houseman ND, Taylor GI, Pan WR (2000) The angiosomes of the head and neck: Anatomic study and clinical applications. PlastReconstr Surg 105: 2287-2313.

24. Banks ND, Hui Chou HG, Tripathi S, Collins BJ, Stanwix MG, et al. (2009) An anatomical study of external carotid artery vascular territories in face and midface flaps for transplantation. Plastic \& Reconstructive Surgery 123: 1677-1687.

25. Rutgers DR, Klijn CJ, Kappelle LJ, Van Huffelen AC, Van der Grond J (2000) A longitudinal study of collateral flow patterns in the circle of will is and the ophthalmic artery in patients with a symptomatic internal carotid artery occlusion. Stroke 31: 1913-1920.

26. Viedma A, Jimenez Ortiz C, Marco V ( 1997) Extended will is circle model to explain clinical observations in periorbital arterial flow. J Biomech 30: 265-272.

27. Frodel JL, Marentette LJ (1993) The Coronal approach. Technical considerations, Anatomical, and morbidity. Arch Otolaryngol Head Neck Surg 119: 201-207.

28. Susmitha R, Tauro D, Bhupesh B, Anuj V (2015) Coronal/ Hemicoronal Approach - A Gateway to Craniomaxillofacial Region. Journal of Clinical and Diagnostic Research 9: PC01-PC05. 